\title{
Effect of annealing on microstructure and hardness of thin aluminium strips fabricated by micro flexible rolling
}

\author{
Mingshuai Huo ${ }^{1,2}$, Jingwei Zhao ${ }^{1}$, Haibo Xie ${ }^{1}$, and Zhengyi Jiang ${ }^{1,2 *}$ \\ ${ }^{1}$ School of Mechanical, Materials, Mechatronic and Biomedical Engineering, University of Wollongong, NSW 2522, Australia \\ ${ }^{2}$ School of Materials and Metallurgy, University of Science and Technology Liaoning, Liaoning 114051, China
}

\begin{abstract}
Thin strips with varying thicknesses (TSVTs) produced by micro flexible rolling have wide applications in diverse micro manufacturing areas such as micro electromechanical systems (MEMS) and micro system technologies (MST). TSVTs consist of three regions based on different thicknesses, i.e. the thicker, the transition and the thinner zones. Among them, the transition zone plays a key role in evaluating the quality of TSVTs. In the current work, thin 1060 aluminium alloy strips were flexibly rolled under various thickness ratios followed by annealing treatment. The influences of annealing temperature on the microstructural evolution and hardness variation of the transition zone of TSVTs were investigated. The results reveal that the recrystallisation has happened after annealing at $400{ }^{\circ} \mathrm{C}$ for $30 \mathrm{~min}$, which induces fine and homogeneously-distributed grains in both of the thinner and transition zones. Only moderate increase in hardness is found from the thicker to the thinner zones after annealing treatment.
\end{abstract}

Keywords: Aluminium, Microstructure, Hardness

\section{Introduction}

Miniaturisation has been an ongoing developing trend in the current technical fields $[1,2]$. It is not only a slogan for energy saving and emission reduction, but also the reflection of the highly demands of micro products, such as connector pins, micro parts for electronics, chip lead frame, micro screws and lead frame, for applications in micro electromechanical systems (MEMS) and micro system technologies (MST) [3, 4]. Micro flexible rolling is a promising microforming technique for the production of thin strips with varying thicknesses (TSVTs), and has attracted an increasing research interests [5]. Qu et al. [6, 7] conducted numerical investigation on the effects of strip thickness, friction coefficient and rolling velocity on the springback during micro flexible rolling technology with considering the grain properties using the 3D Voronoi tessellation method. Zhao et al. [8] analysed the size effects involved in micro flexible rolling of metals.

Annealing has an important effect on the microstructure, texture, dislocations and stored energy of the plastically deformed materials, and in turn influences the properties of final products. Unfortunately, literature reporting the annealing effect of TSVTs is still unavailable so far. In current study, TSVTs with different thickness ratios (the ratio of thickness at thicker zone to that of thinner zone) have been treated under different annealing conditions in order to delineate the

\footnotetext{
*Corresponding author: jiang@uow.edu.au
}

effect of annealing on the characteristics including the microstructure evolution and hardness distribution.

\section{Experimental}

1060 aluminium strips with a thickness of $464 \mu \mathrm{m}$ were cut into $150 \mathrm{~mm} \times 15 \mathrm{~mm}$, and then annealed at $500{ }^{\circ} \mathrm{C}$ for $2 \mathrm{~h}$ in order to obtain fully recrystallised grains. Following this, they were micro flexibly rolled into different thickness ratios (the ratio of thickness at the thicker zone to that of the thinner zone) in terms of the rolling schedule shown in Table 1 . In which, $R_{1}=T_{1} / T_{0}$ and $R_{2}=T_{2} / T_{0}$. The diameter and roll barrel length of the work roll are 25 and $40 \mathrm{~mm}$, respectively.

Table 1 Rolling schedule of Group 1.

\begin{tabular}{llll}
\hline Rolling parameters & S1 & S2 & S3 \\
\hline Initial thickness $T_{0}(\mu \mathrm{m})$ & 464 & 464 & 464 \\
Thickness at thicker zone $T_{I}(\mu \mathrm{m})$ & 346 & 346 & 346 \\
Reduction at thicker zone $R_{I}(\%)$ & 25.4 & 25.4 & 25.4 \\
Thickness at thinner zone $T_{2}(\mu \mathrm{m})$ & 96 & 172 & 245 \\
Reduction at thinner zone $R_{2}(\%)$ & 79.3 & 62.9 & 47.2 \\
Thickness ratio & 3.60 & 2.01 & 1.41 \\
Rolling speed $(\mathrm{cm} / \mathrm{min})$ & 60 & 60 & 60 \\
\hline
\end{tabular}

Annealing heat treatment was applied to all the flexibly-rolled specimens. The detailed procedures are 
shown in Fig. 1. One batch of specimens was isothermally annealed at $400{ }^{\circ} \mathrm{C}$ for varying holding times in the range of 10-60 $\mathrm{min}$, and the other batch was isochronally annealed at 200, 300 and $400{ }^{\circ} \mathrm{C}$ respectively, for $30 \mathrm{~min}$. All the heat-treated specimens were water-quenched after corresponding annealing processes.

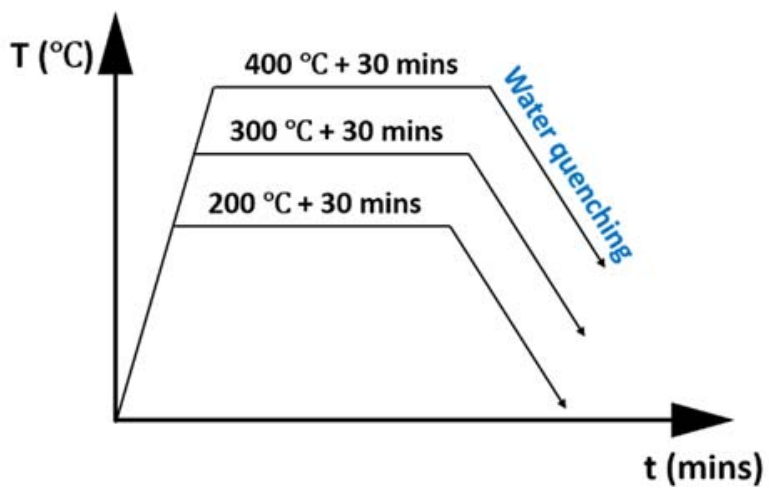

Fig. 1 Flow chart for various target specimens.

All the samples were ground and polished to the colloidal silica stage on a Struers Tegramin and electrolytic etching using Barker's reagent with Struers Lectropol 5. Subsequently, Leica DMRM and Nikon Fluorescence Microscope were used for the identification and acquisition of the polarised light false colour optical micrographs from longitudinal sections as defined by the rolling direction (RD) and the normal direction (ND).

Vickers hardness testing was conducted at five preset points on the cross-sectional surfaces of the TSVTs through the thicker, transition and thinner zones along the rolling direction, as shown in Fig. 2. A TIME TH715 Microhardness tester was used with a $4.9 \mathrm{~N}$ load and a dwelling time of $10 \mathrm{~s}$ for all the specimens with three duplicate tests.

\section{Results and discussion}

\subsection{Microstructural evolution}

Fig. 3 shows the initial microstructure of aluminium strip after homogenisation annealing carried out at $500{ }^{\circ} \mathrm{C}$ for
$2 \mathrm{~h}$. It can be seen that the recrystallised microstructure with equiaxed grains has been obtained.

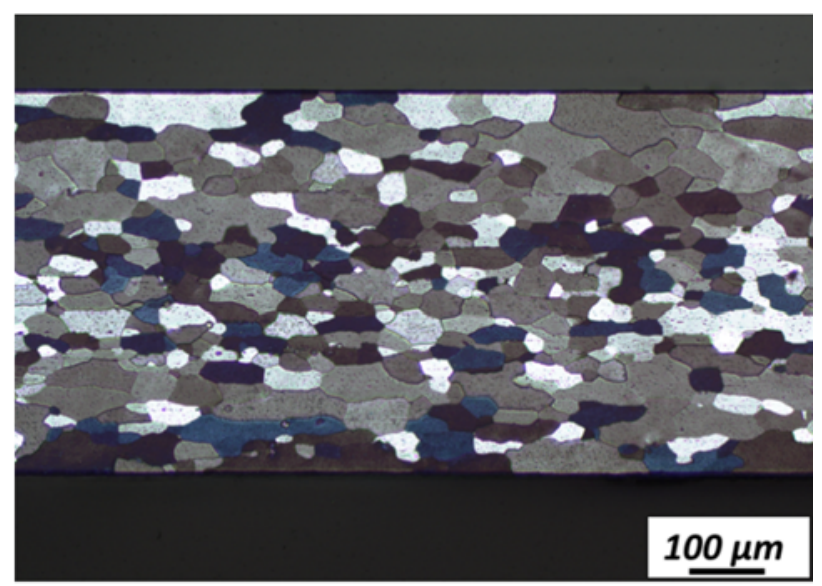

Fig. 3 Initial microstructure after fully recrystallisation at 500 ${ }^{\circ} \mathrm{C}$ annealing for $2 \mathrm{~h}$.

After micro flexible rolling with three thickness ratios, different thickness variations and grain characteristics from the thinner zone to the thicker zone of S1-S3 can be observed, as shown in Fig. 4. Apparently, the grains distribution and the grain size have changed to a large extent in the thinner and transition zones compared with the initial condition (Fig. 3 ), while only a little variation happened in the thicker zone because of the relatively small rolling reduction. In the thinner zones (Fig. 4a, d and g), nearly entire elongated grains are aligned parallel to the rolling direction have been observed. Largest reduction applied to $\mathrm{S} 1$ presents the most severe microstructural deformation with the longest aspect ratio of the elongated bands with the most densely lamellar space. Typical waved characteristics have been found in the middle layer in all the thinner zones of TSVTs, and meanwhile some shear bands have formed at the surface layers, which are caused in the rolling process with a reduction of above 50\% [9]. For the transition zones, microstructure near the top and bottom surfaces always deform as the rolling schedules. The lamellar spaces of the grains decrease gradually with the increase of the rolling degrees. Besides, the waved characteristics also arise especially near the thinner zone sides.

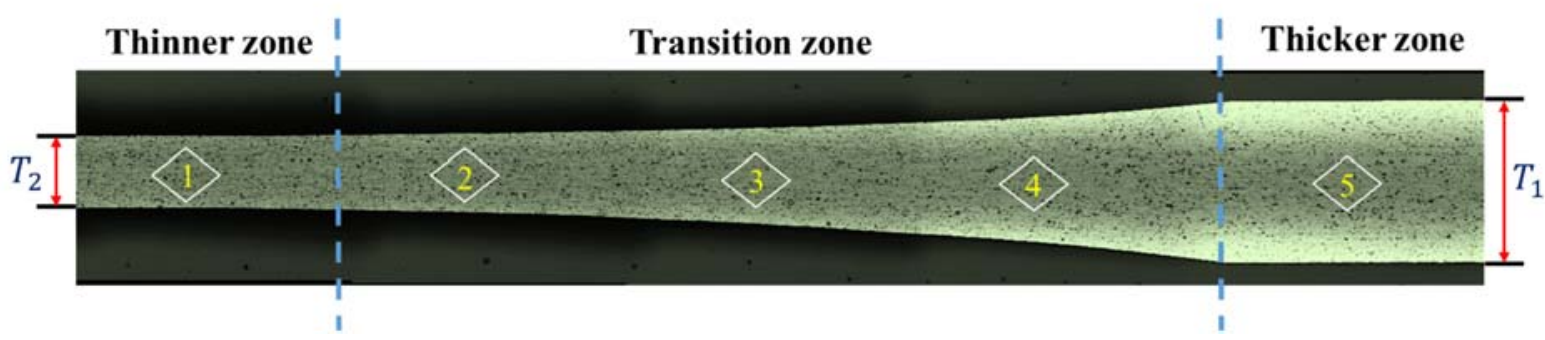

Fig. 2 Measured hardness positions in the thicker zone, transition zone and thinner zone. 


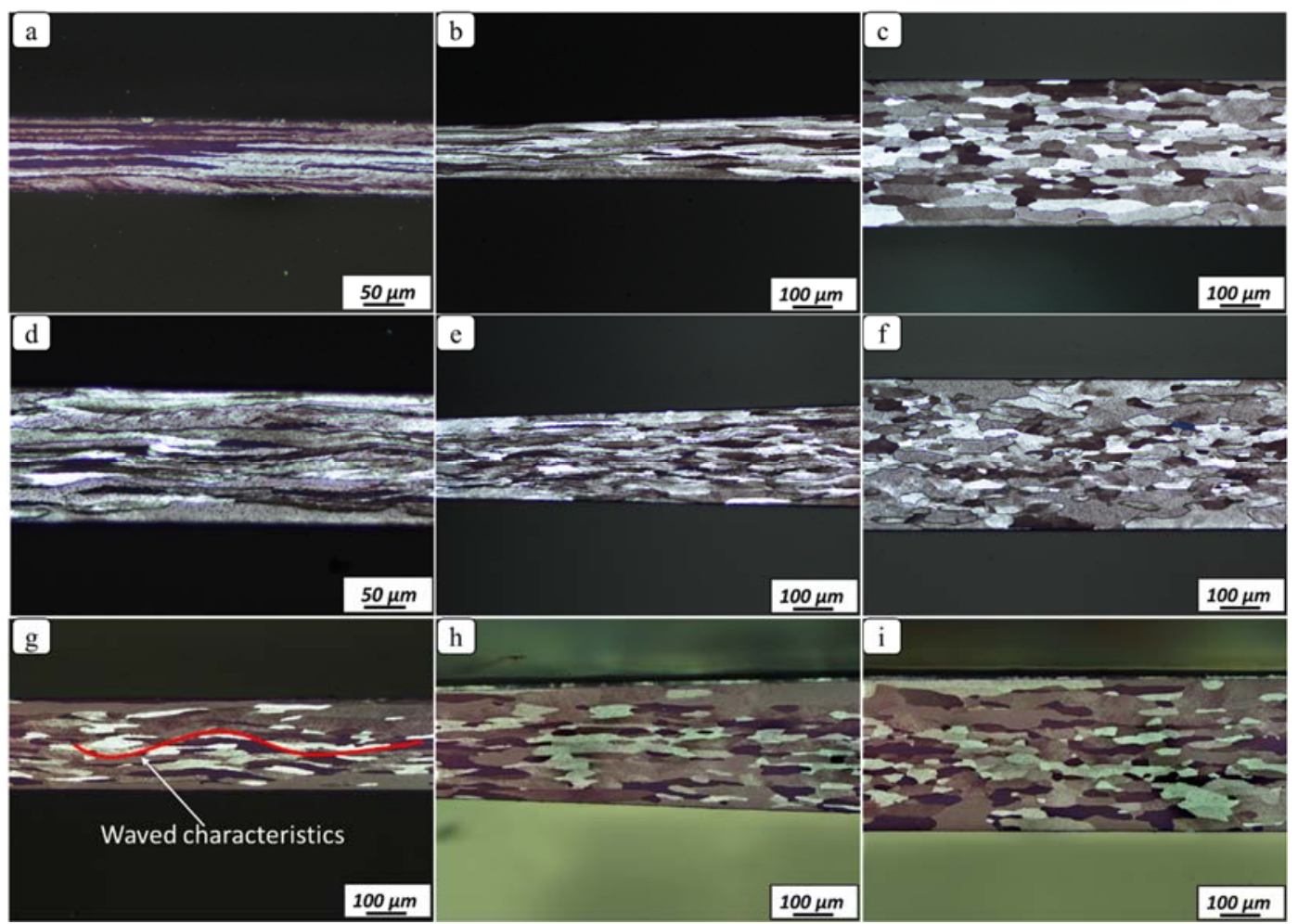

Fig. 4 Microstructure distribution after micro flexible rolling in the thinner zones of (a) S1, (d) S2, (g) S3, the transition zones of (b) S1, (e) S2, (h) S3 and the thicker zones (c) S1, (f) S2, (i) S3.

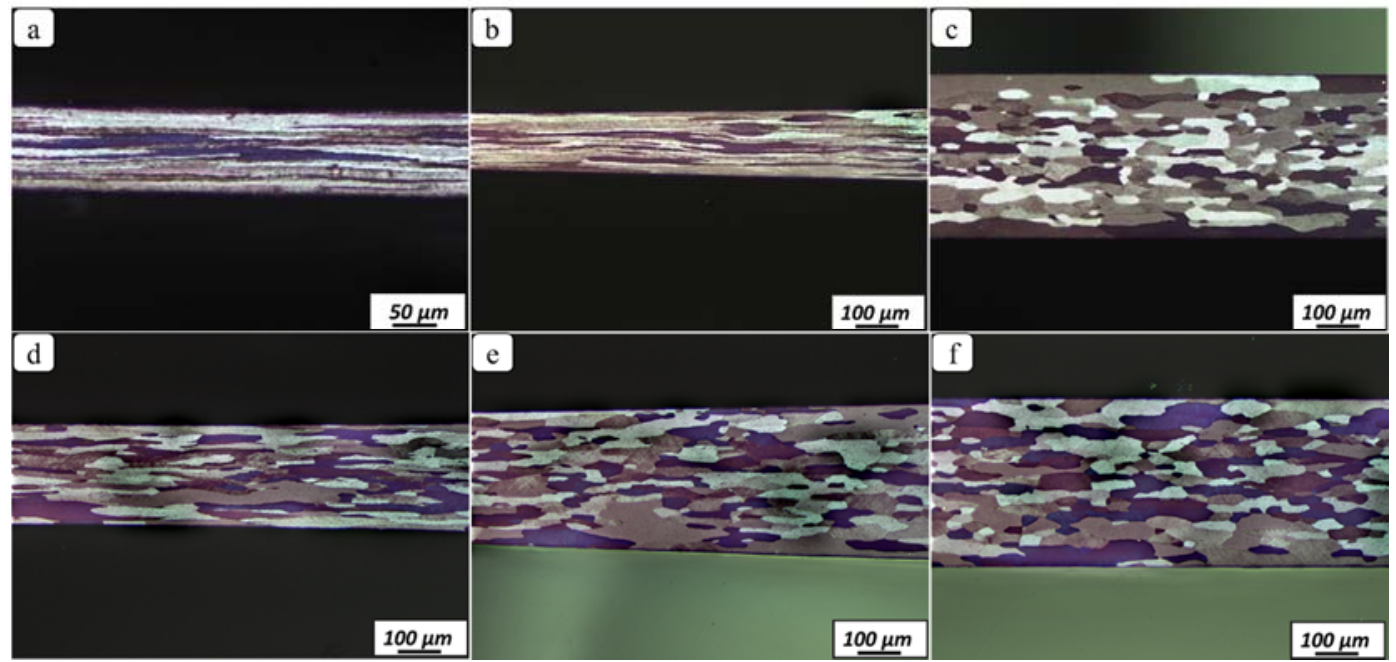

Fig. 5 Microstructure distribution after isochronal annealing at $200{ }^{\circ} \mathrm{C}$ in the thinner zones of (a) $\mathrm{S} 1$, (d) S3, the transition zones of (b) S1, (e) S3 and the thicker zones (c) S1, (f) S3.

Fig. 5 shows the microstructure of $\mathrm{S} 1$ and $\mathrm{S} 3$ after annealing at $200{ }^{\circ} \mathrm{C}$ for $30 \mathrm{~min}$. Comparing with the micro flexibly rolled results (Fig. 4), no apparent influence on the TSVTs is found, which means annealing at $200{ }^{\circ} \mathrm{C}$ is not sufficient for recovery or recrystallisation. Comparatively, a slight change occurs when the annealing temperature arises to $300{ }^{\circ} \mathrm{C}$, as shown in Fig. 6. With regards to the thinner zones (Fig. 4), there is almost no obvious waved characteristics presenting in both thinner and transition zones. This results in the release of the deformation stored energies from strain hardening and residual stress. The grains become more closely aligned with the rolling plane, which means recovery phenomenon has occurred at this annealing temperature. The same situation has appeared in the transition zone (Fig. $6 \mathrm{~b}$ and e) that the lamellar grains in the top and bottom layers display a similar distribution characteristic along the surface layers apart from the grains in the middle layer parallel to the rolling plane.

When raising the annealing temperature to $400{ }^{\circ} \mathrm{C}$, as shown in Fig. 7, TSVTs in the thinner and transition zones reveal the salient variations although almost no apparent change occurs in the thicker zones. The reason 


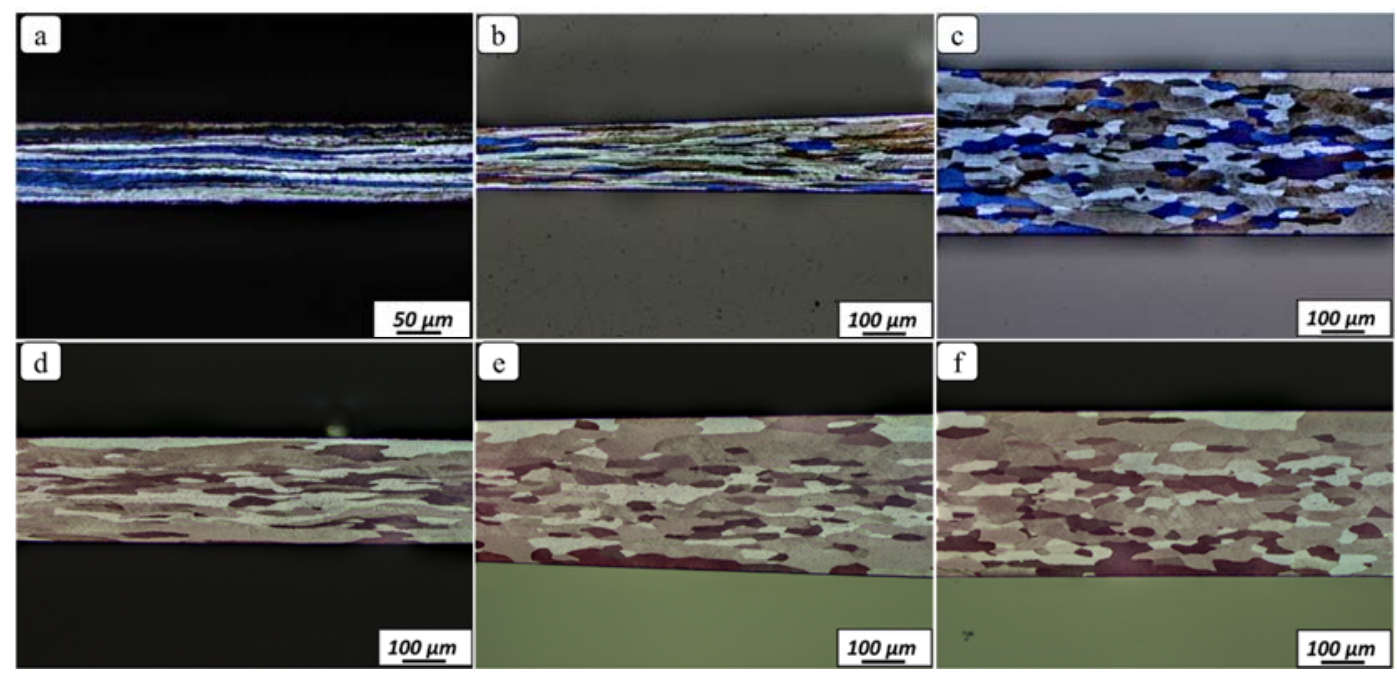

Fig. 6 Microstructure distribution after isochronal annealing at $300^{\circ} \mathrm{C}$ in the thinner zones of (a) S1, (d) S3, the transition zones of (b) $\mathrm{S} 1$, (e) S3 and the thicker zones (c) S1, (f) S3.

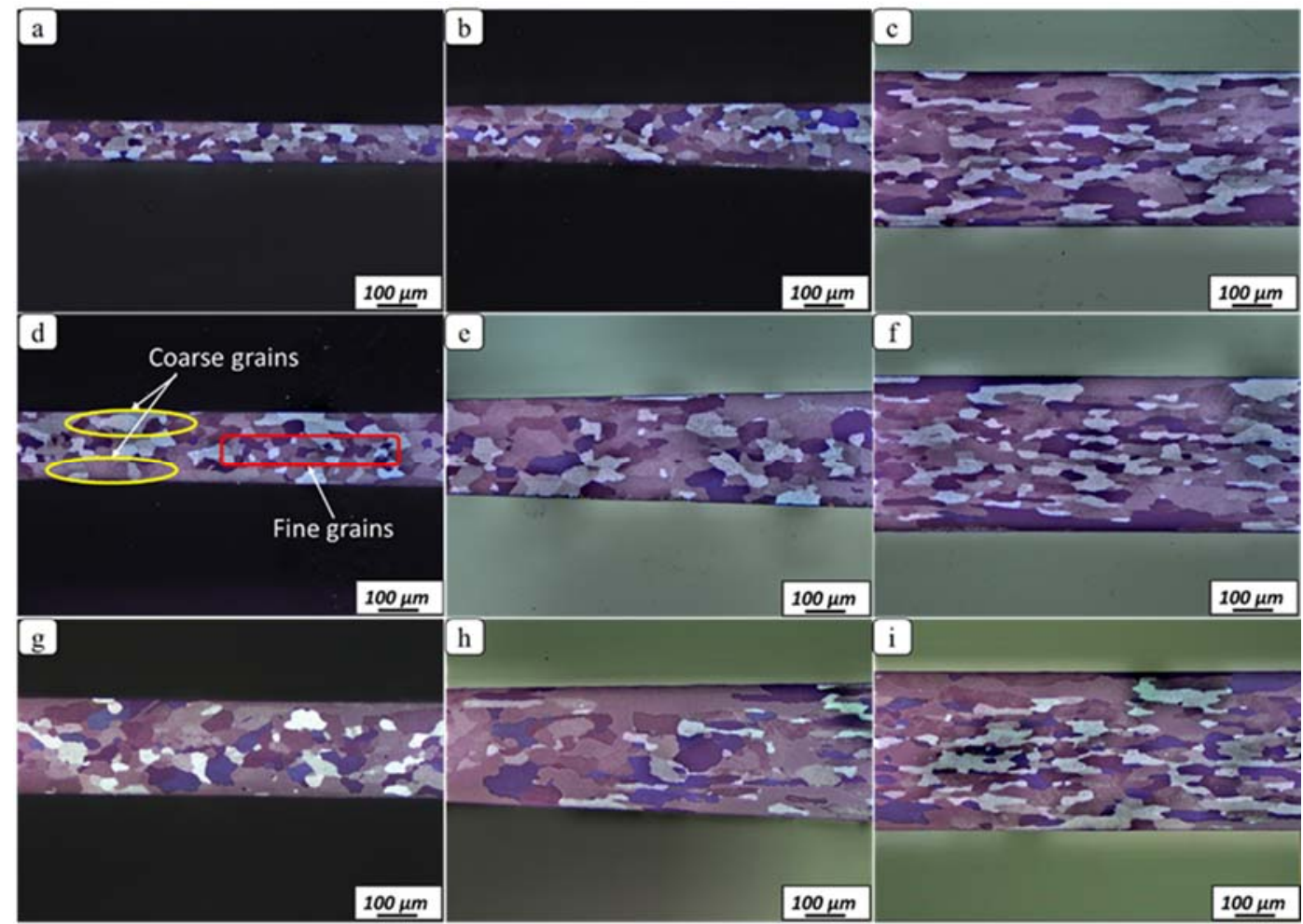

Fig. 7 Microstructure distribution after isochronal annealing at $400^{\circ} \mathrm{C}$ in the thinner zones of (a) S1, (d) S2, (g) S3, the transition zones of (b) S1, (e) S2, (h) S3 and the thicker zones (c) S1, (f) S2, (i) S3.

is that the higher reductions at the thinner and transition zones lead to more stored energy, which provides more driving force for recrystallisation. This provides large density of nucleating sites for recrystallisation, contributing to the formation of fine grains. Grain refinement is beneficial for the improvement in mechanical properties based on the well-known HallPetch relationship [10]. However, fine grains tend to emerge in the middle layer comparing with coarse grains near the surface layers. It is thought that the high dislocation density in the areas resulting from the shear deformation generates more stored energy. This is also the cause of the recrystallisation gradient in the transition zone, as shown in Fig. 7(h).

\subsection{Hardness}

Hardness results after micro flexible rolling and subsequent annealing processes are given in Figs. 8 and 9, from which a climbing trend from the thicker to the thinner zones has been observed. With the decrease of thickness ratio from $\mathrm{S} 1$ to $\mathrm{S} 3$, the hardness value reduces gradually at each measured position. This phenomenon can be explained that the increase of reduction leads to 
the growth of strain hardening. Dislocation tangles with high density are the keys to boost the intensity of this hardening behaviour [11].

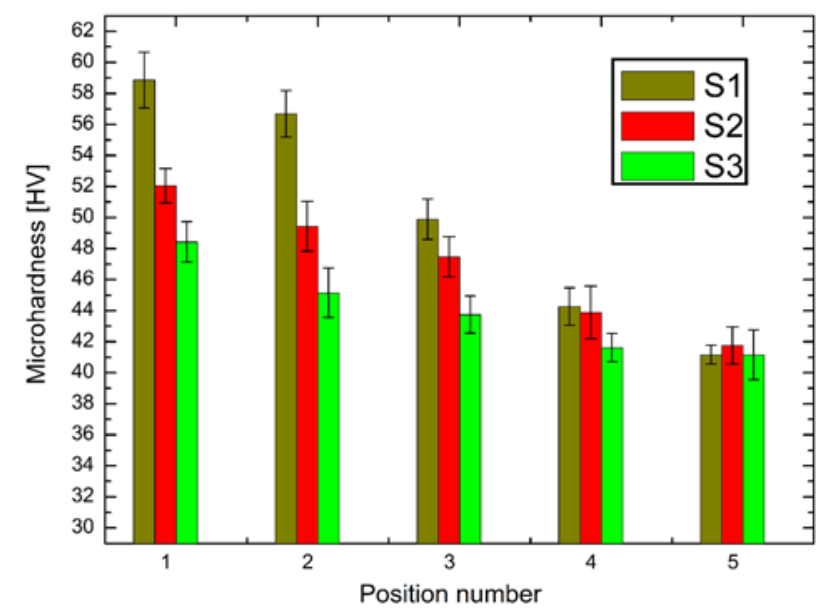

Fig. 8. Variations in Vickers hardness after micro flexible rolling with different thickness ratios.

As the microstructure of TSVTs under different annealing conditions presents a similar trend, S1 specimen with the highest thickness ratio after annealing has been taken for hardness measurements. Fig. 9 shows that all the specimens exhibit a decreasing trend with the increase of temperature from 200 to $400{ }^{\circ} \mathrm{C}$, no matter in the thinner, thicker or transition zones. It is clear that specimens annealed at $400{ }^{\circ} \mathrm{C}$ for $30 \mathrm{~min}$ exhibit smooth hardness distribution, and only moderate increase in hardness is found throughout the various thickness zones.

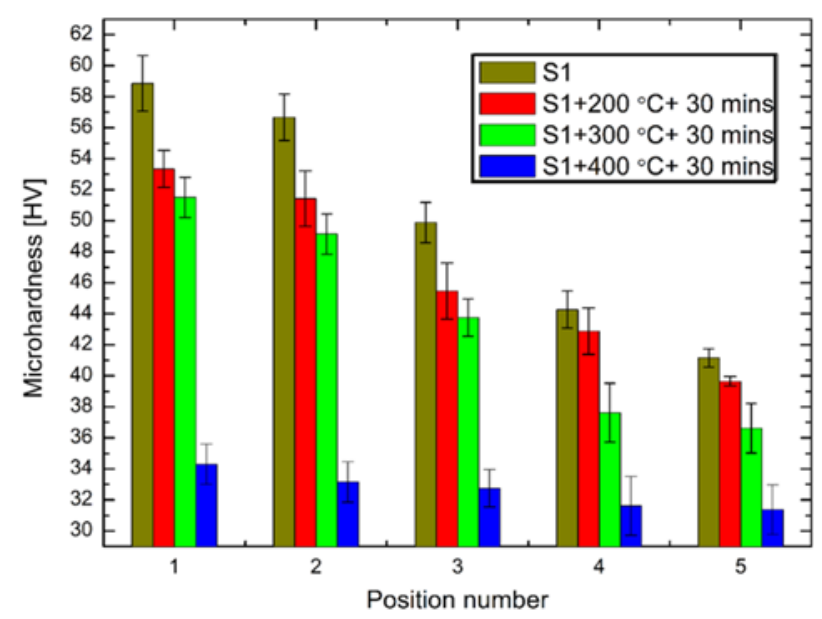

Fig. 9. Variations in Vickers hardness of $\mathrm{S} 1$ after annealing at 200, 300 and $400{ }^{\circ} \mathrm{C}$ for $30 \mathrm{~min}$.

\section{Conclusions}

The effect of annealing temperature on the microstructure and hardness of thin 1060 aluminium alloy strips was investigated. The following conclusions can be drawn from the current research:
(1) The annealing temperature significantly affects the grain shapes, size and distribution of TSVTs. Recrystallisation results in fine grains in both of the thinner and transition zones after annealing at 400 ${ }^{\circ} \mathrm{C}$.

(2) A relatively steady hardness distribution is observed when TSVTs is annealed at $400{ }^{\circ} \mathrm{C} 30 \mathrm{~min}$, and the hardness increases moderately through the thicker to thinner zones.

\section{Acknowledgements}

The first author gratefully appreciates UOW for $\mathrm{PhD}$ scholarship. This study is also supported by the grant from Australian Research Council (ARC, Grant No. FT120100432) and National Natural Science Foundation of China under Grant No. 51474127.

\section{References}

[1] U. Engel, R. Eckstein, Journal of Materials Processing Technology 125 (2002) 35-44.

[2] M. Geiger, M. Kleiner, R. Eckstein, N. Tiesler, U. Engel, Cirp Annals-Manufacturing Technology 50 (2001) 445-462.

[3] W.L. Chan, M.W. Fu, J. Lu, Materials \& Design 32 (2011) 198-206.

[4] Q. Zheng, T. Shimizu, M. Yang, International Journal of Mechanical Sciences 133 (2017) 416425.

[5] Z. Jiang, J. Zhao, H. Xie, Microforming Technology: Theory, Simulation and Practice (2017).

[6] F. Qu, Z. Jiang, H. Lu, International Journal of Mechanical Sciences 105 (2016) 182-190.

[7] F. Qu, Z. Jiang, D. Wei, Q. Chen, H. Lu, International Journal of Mechanical Sciences 123 (2017) 324-339.

[8] J. Zhao, H. Xie, H. Lu, Z. Jiang, Size effects in micro rolling of metals, IOP Conference Series: Materials Science and Engineering, vol 282, 2017.

[9] P.J. Hurley, F.J. Humphreys, Acta Materialia 51 (2003) 1087-1102.

[10] W. Chrominski, S. Wenner, C.D. Marioara, R. Holmestad, M. Lewandowska, Materials Science and Engineering: A 669 (2016) 447-458.

[11] B. Wang, X. Chen, F. Pan, J. Mao, Y. Fang, Transactions of Nonferrous Metals Society of China 25 (2015) 2481-2489. 